\title{
Lo solemne y lo festivo: contrastes y paralelismos en el primer ciclo de historias de Los cuentos de Canterbury
}

\section{Aurora PIÑEIRO Universidad Nacional Autónoma de México}

\begin{abstract}
We are so made that we can derive intense enjoyment only from a contrast and very little from a state of things.
\end{abstract}

Sigmund Freud

Los cuentos de Canterbury son la última e inconclusa obra del afamado escritor inglés Geoffrey Chaucer (1340-1400). El libro es, en términos de una carrera literaria, el producto de la madurez intelectual y la prueba de que su autor había alcanzado una libertad de expresión que en obras anteriores tal vez sólo quedaba insinuada. Los cuentos de Canterbury son considerados, por muchos críticos, no sólo lo más deslumbrante de la producción de Chaucer, sino el libro más representativo de la literatura inglesa medieval. Se trata de una colección de relatos hilvanada por otro tipo de textos, que parte de la historia de un peregrinaje a Canterbury, como pretexto literario. Así, coinciden en una posada en Southwark treinta y tres peregrinos que aceptan el reto de viajar juntos hasta el conocido santuario y competir por una cena gratis narrando dos historias en el camino a Canterbury, y dos más durante el recorrido de vuelta. Aunque Chaucer sólo alcanzó a elaborar las descripciones de veintiséis de los peregrinos y veinticuatro cuentos, la obra nos brinda acabadísimos ejemplos de textos literarios que no necesitan más "revisiones" que las múltiples lecturas que de ellos hacemos los adictos al autor.

La gran mayoría de las ediciones de Los cuentos de Canterbury parten del manuscrito de Ellesmere que agrupa a los textos en diez secciones. La primera de ellas es la compuesta por el "Prólogo general", "El cuento del caballero", el "Diálogo entre el anfitrión y el molinero", "El cuento del molinero", el "Prólogo al cuento del administrador", el "Cuento del administrador", el "Prólogo al cuento del cocinero" y el incompleto "Cuento del coci- 
nero". De estos textos que constituyen el primer ciclo de la colección seleccioné los dos primeros cuentos, el del caballero y el del molinero, para ejemplificar la manera en que Chaucer utiliza recursos como los paralelismos y los contrastes para jugar con propuestas literarias y filosóficas polarizadas.

Empecemos por el caballero y su historia, inspirada en la Teseida de Boccaccio. Ya en el "Prólogo general" se nos había dicho que

A knight ther was, and that a worthy man,

That fro the tyme that he first bigan

To ryden out, he loved chivalrye,

Trouthe and honour, freedom and curteisye. (Chaucer 1977: 2)

(There was a knight, a most distinguished man,

Who from the day on which he first began

To ride abroad had followed chivalry,

Truth, honor, generousness and courtesy.) (Chaucer 1977: 20)

Se nos informa que el caballero - de quien no sabemos su nombre porque es un personaje "tipo" - ha participado en importantes campañas militares, y que su atuendo aún guarda las huellas de la última batalla: tanta era su piedad y su prisa por unirse a la peregrinación que aún llevaba la ropa manchada por el hollín de su armadura. Dada la descripción del personaje, no podíamos esperar del mismo una historia que no fuera un romance cortés. Pero el caballero hace que su romance se desarrolle en la antigua Grecia, en Atenas, cuando dicha ciudad era gobernada por el duque Teseo (Theseus). En otras palabras, el gran guerrero de la cristiandad elige un contexto no cristiano para una historia que, sin embargo, nos da una versión medievalizada del clasicismo helénico. El caballero no puede disimular la admiración que le inspira la figura de Teseo, sus hazañas heroicas e incluso su conquista de Hipólita, la reina de las amazonas. De hecho, la historia comienza con la vuelta a Atenas del victorioso héroe, su esposa y Emilia, la hermana más joven de la misma. Pero antes de llegar al palacio, la comitiva se encuentra con un grupo de viudas que le suplican a Teseo vengar la muerte de sus esposos. Así, el duque tiene que partir a una batalla más, de la cual saldrá victorioso y volverá a casa con dos prisioneros de guerra: dos jóvenes tebanos, de origen noble, encontrados malheridos entre los cadáveres que cubrían el campo de batalla. Los prisioneros, Palamon y Arcite, son encarcelados en una torre y lamentan no haber logrado, mejor, una muerte digna en la batalla. Pero el ánimo melancólico de los guerreros es sustituido por una pasión violenta cuando, una mañana del mes de mayo, Palamon 
descubre a una hermosa doncella cortando flores en un jardín ubicado junto a la torre que los mantiene prisioneros. Palamon sufre el flechazo amoroso y deja escapar un grito que su compañero Arcite interpreta como un signo de desesperación. Y a estas alturas de la historia, Chaucer ya ha introducido uno de los temas que están presentes a lo largo de toda su obra: el tema de la fortuna, ante el cual el autor suele mantener una postura ambigua.

La dificultad que los estudiosos medievales encontraron para conciliar conceptos como "destino", "castigo divino" o "infierno", entre otros, con la idea cristiana de "libre albedrío", los llevó a la formulación de términos como el de "providencia": la idea, tampoco muy satisfactoria, de un dios que sabe y provee, pero no determina. Sin embargo, Chaucer utiliza en muchas de sus historias el término "fortuna" y, en la mayor parte de las ocasiones, no queda claro si se refiere a una fuerza externa al control humano, pero gobernada por el dios monoteísta, o a una potencia autónoma. Éste no es, sin embargo, el caso del cuento del caballero. En esta narración, la fortuna sí es una fuerza identificada con la idea clásica de destino, y controla la existencia humana de una forma arbitraria y cruel, de ahí la necesidad de ubicar el relato en un contexto pagano. Cuando Arcite interpreta el grito de Palamon como una muestra de desesperación ante la adversidad, lo llama a la cordura con las siguientes palabras:

For Goddes love, tak al in pacience

Our prisoun, for it may non other be;

Fortune hath yeven us this adversitee.

Som wikke aspect or disposicioun

Of Saturne, by sum constellacioun,

Hath yeven us this, al-though we hadde it sworn;

So stood the heven whan that we were born;

We moste endure it: this is the short and pleyn.' (Chaucer 1977: 32)

(For God's love, take things patiently, have sense,

Think! We are prisoners and shall always be.

Fortune has given us this adversity,

Some wicked planetary dispensation,

Some Saturn's trick or evil constellation

Has gives us this, and Heaven, though we had sworn

The contrary, so stood when we were born.) (Chaucer 1977: 48)

Las líneas anteriores se afilian a la concepción fatalista característica de la cosmovisión clásica, aunque se incluya una frase como "por amor de Dios", que prueba la medievalización del discurso. Es una ironía trágica, además, 
el que haga referencia a "algún truco de Saturno", dios que, en complicidad con Venus, causará su desgracia al final de la historia.

Sin embargo, unos versos después de la cita anterior, descubre al objeto de la agitación de su compañero y es flechado también por la visión de la doncella, quien no es otra que la inocente Emelye, transformada en el ideal femenino del romance cortés. Así se inicia una disputa entre los caballeros por el amor de una dama inalcanzable, una de las convenciones del género citado. Pero los ahora rivales representan facetas distintas del amor. Cuando Palamon descubre a la damisela, su primer impulso es adorarla, creyendo que se trata de la diosa Venus (nótese que se utiliza la terminología latina para nombrar a los dioses, como era propio del discurso medieval); mientras que Arcite se enamora de ella como mujer, así que el propio Arcite explica: "Thyn is affeccioun of holinesse, / And myn is love, as to a creature" (Chaucer 1977: 48). ("Yours is a mystical, a holy love, / And mine is love as to a human being".) (Chaucer 1977: 50) A primera vista, podría interpretarse esta diferencia como una típica confrontación de los conceptos de amor sagrado versus amor profano, aunque en realidad se trata de dos caras del mismo amor cortés que, contrario a lo que muchas veces se piensa, sí podía incluir la consumación del mismo en el encuentro carnal de los amantes, sin dejar de ser una forma de amor que ennoblecía a los involucrados: la clave estaba en que la relación se diera entre iguales (entiéndase dos personas de origen noble) y en que se respetaran ciertos procedimientos en el ámbito público y en el privado. Lo anterior nos habla de una idea aristocrática del amor en conflicto con virtudes cristianas como la castidad o la fidelidad.

De esta manera, tanto Palamon como Arcite, nobles caballeros, están cortésmente enamorados de una Emelye que ya no es descrita como amazona, sino como una casta dama medieval, idea que se refuerza con su aparición en el jardín asociada a los lirios y las primeras rosas de mayo. No deja de ser irónica la violencia del enamoramiento a primera vista que ha tornado en enemigos a dos jóvenes cuya situación como prisioneros se convierte, también, en símbolo de la condición humana y su constante anhelo de lo inalcanzable.

Por un giro de la Fortuna, Arcite es liberado bajo condición de no volver jamás a la ciudad de Atenas, so pena de muerte. El caballero que antes soñaba con la libertad, languidece ahora por estar privado de la vista de su amada y envidia la condición del prisionero que tiene el consuelo de verla cortar flores desde la única ventana de su celda. Así, el personaje decide renunciar a su libertad y hacerse pasar por esclavo al servicio de la casa de Teseo, para poder contemplar, de lejos, al objeto de su amor. Años después, Palamon es misteriosamente ayudado a escapar y, en su refugio, en las afueras de la 
ciudad, escucha los lamentos de un Arcite avergonzado de vivir negando su identidad, engañando a sus amos y, a final de cuentas, privado del amor de Emelye. Los rivales se enfrentan y, por obra de Dios, el destino y la providencia, todos puestos a trabajar en una misma estrofa, Teseo decide salir de cacería en esa ocasión y se encuentra con los ex prisioneros librando una sangrienta batalla. Veamos primero la estrofa aludida:

The destinee, ministre general,

That executeth in the world over-al

The purveyaunce, that God hath seyn biforn,

So strong it is, that, though the world had sworn

The contrarie of a thing, by ye or nay,

Yet somtyme it shal fallen on a day

That falleth nat eft with-inne a thousand yere.

For certeinly, our appetytes here,

$\mathrm{Be}$ it of werre, or pees, or hate, or love,

All is this reuled by the sighte above. (Chaucer 1977: 48)

(Now Destiny, that Minister-General

Who executes on earth and over all

What God, from everlasting, has foreseen,

Is of such strength, that though the world had been

Sure of the contrary, by Yea and Nay,

That thing will happen on a certain day,

Though never again within a thousand years.

And certainly our appetites and fears,

Whether in war or peace, in hate or love,

Are governed by a providence above.) (Chaucer 1987: 64)

La estrofa anterior intenta reconciliar al Destino con la idea de Dios, subordinando el primero al segundo, pero nos sigue causando problemas el uso de un término como foreseen y, por supuesto, la "explicación" de que lo dispuesto por Dios sucederá aunque el mundo entero esté convencido de lo contrario.

Los términos en los que está descrito el combate entre aquellos que en el pasado habían sido amigos y compañeros de armas denotan una animalización de los personajes:

Thou mightest wene that this Palamoun

In his fighting were a wood leoun,

And as a cruel tygre was:

As wilde bores gone they to smyte,

That frothen whyte as foom for ire wood. (Chaucer 1977: 48) 
(You would have thought, seeing Palamon engage,

He was a lion fighting-mad with rage,

a cruel tiger, as they beat

And smote each other, or as boars that meet

And froth as white as foam upon the flood.) (Chaucer 1977: 63-64)

Aquí ya no estamos en el terreno del amor cortés que ennoblece, sino en el territorio de la influencia de Boecio, en particular de su obra El consuelo de la filosofía; en la literatura de Chaucer: la violencia de la pasión degrada al hombre, lo reduce a la condición animal.

Teseo descubre a los combatientes y ordena que la pelea se lleve a cabo en condiciones civilizadas, es decir, en una arena, con público y jueces, y sin ser una batalla a muerte. El hecho de que la pelea esté regulada los honra, como caballeros, y los devuelve al contexto de lo heroico, pero no los exime, como humanos, del arbitrio de la Fortuna.

Antes del combate, Palamon visita el templo de Venus, diosa a la que se refirió al contemplar a Emelye por vez primera. Arcite acude al templo de Marte, y Emelye ofrece sacrificios a Diana. Ésta es la primera ocasión en que tenemos acceso a la mente del personaje femenino y descubrimos que le pide a la diosa que conserve su castidad y la libre del enlace con cualquiera de los pretendientes, ya que la amada en disputa no está interesada en ninguno de los dos. El culto a Diana relaciona al personaje con sus orígenes como amazona, pero la diosa pagana puede ser también un símbolo de la virtud cristiana de la castidad. El acento trágico está en el hecho de que Emilia, al igual que los pretendientes, está sometida a por lo menos dos formas irrefutables de autoridad: la terrenal, representada en Teseo, su cuñado y gobernador, y la sobrenatural, encarnada en la Fortuna.

Arcite, que se había encomendado a Marte, gana la batalla; pero Saturno, influido por Venus, desata un temblor de tierra y provoca la muerte del triunfador, recibiendo Palamon el derecho a desposar a Emilia. El final del cuento del caballero demuestra que la existencia humana está sujeta al capricho de los dioses y que, en términos del amor cortés, la admiración que el narrador expresa en diversas ocasiones por el personaje de Palamon, junto con el final de la historia, revela una preferencia por la faceta del amor cortés que tiene que ver con lo sagrado o místico. Lo terrenal queda desvalorizado, incluso los deseos de victoria, en términos bélicos, de Arcite.

No obstante el pesimismo filosófico que permea al cuento del caballero, la historia es recibida con agrado por el resto de los peregrinos, pero el hecho mismo de que el caballero resulte, después de un juego de azar, el elegido para narrar la primera historia es un reflejo al exterior del relato de la 
falta de control que sobre la existencia tienen no sólo los personajes del cuento, sino los personajes de Chaucer en el libro y, por un juego especular, los lectores. Aunque, claro, muchos críticos están de acuerdo en que es una inteligente estrategia literaria el colocar el cuento del caballero al inicio de la colección, respetando las jerarquías sociales de la época. Para ser coherente con esas jerarquías, el anfitrión pide al monje que narre una historia y, así, coloca a la clase guerrera y al clero como cabezas del peregrinaje a Canterbury y, en términos alegóricos, como guías de la humanidad en su peregrinar hacia la salvación.

Sólo que el anfitrión no contaba con la necedad del molinero, quien, con una buena dosis de alcohol en la venas, decide que va a contar una historia tan deleitosa como la del caballero. Aquí tenemos ya un primer elemento transgresor que consiste en la alteración de las jerarquías: un personaje de un estrato social inferior y de dudosa calidad moral ${ }^{1}$ relatará la historia que será la contraparte del romance del caballero. Se trata nada menos que de una fabliau, una historia cómica, generalmente narrada en verso, cuyos personajes más recurrentes son el marido cornudo, la esposa infiel y al menos un joven seductor que gana los favores amorosos de la anterior. "El cuento del molinero", como toda fabliau, es sexualmente explícito y no le ahorra al lector o a la audiencia detalles obscenos tanto en el nivel del lenguaje, como en el de las acciones. La anécdota tiene que ver con un viejo carpintero que se casa con una joven de dieciocho años. El carpintero renta una habitación a un estudiante que, para conseguir una noche de placer con la encantadora Alison, desarrolla una estrategia que mantendrá entretenido al esposo hasta el amanecer. La treta consiste en hacerle creer a John, el carpintero, que Dios enviará un segundo diluvio a la tierra y que lo ha elegido a él como el nuevo Noé. El ingenuo personaje nunca se cuestiona por qué, de entre todos los seres de la tierra, ha sido privilegiado con esa oportuna información: su amor por Alison sólo le permite pensar en qué hará para salvarla de la destrucción general. Siguiendo paso a paso los consejos de Nicholas, el estudiante, John cuelga tres barriles del techo del segundo piso de su casa para que, cuando el desastre inicie, los tres habitantes de la misma puedan "navegar" sobre las aguas que destruirán a la humanidad. Llegada la noche fatal, cada personaje se introduce en su barril respectivo y, según instrucciones del "visionario" Nicholas, empiezan a rezar para que la catástrofe los alcan-

${ }^{1}$ La cuestionable calidad moral del molinero está insinuada en el "Prólogo general", entre otros rasgos, por su sospechosa barba roja. La tradición medieval atribuía a Judas, el traidor, una barba roja, por lo tanto, todos los pelirrojos eran sujetos en los que no se podía confiar. 
ce en estado de oración. Al ritmo arrullador de los rezos, John empieza a roncar y los jóvenes aprovechan la ocasión para pasar una noche de placer en el lecho marital. Todo marcha de maravilla hasta que se presenta a la ventana de Alison otro pretendiente, Absolon, que le lleva serenata.

Hasta este momento, podemos notar que hay ya varios paralelismos entre la historia del caballero y la del molinero, sólo que con una constante inversión de los términos. El elemento más obvio es el del triángulo amoroso. Tenemos a dos jóvenes gallardos compitiendo por el amor de una misma mujer, pero se trata, en la segunda historia, de un estudiante mentiroso y un sacristán exhibicionista. Y en el caso del personaje femenino, tenemos a una esposa desleal, en lugar de una casta dama. Los personajes típicos del romance cortés han sido sustituidos por los de una clase media urbana de aspiraciones mundanas. El tono contrastante de los cuentos es identificable desde sus primeros versos. La historia del caballero inicia con las siguientes líneas:

Whylom, as olde stories tellen us,

Ther was a duk that highte Theseus;

Of Athenes he was lord and governour,

And in his tyme swich a conquerour,

That gretter was ther noon under the sonne. (Chaucer 1977: 26)

(Stories of old have made it known to us

That there was once a Duke called Theseus,

Ruler of Athens, Lord and Governor,

And in his time so great a conqueror

There was none mightier beneath the sun.) (Chaucer 1977: 42)

Frente a los versos iniciales del cuento del molinero:

Whylom ther was dwellinge at Oxenford

A riche gnof, that gestes heeld to bord,

And of his craft he was a Carpenter.

With him ther was dwellinge a povre scoler,

Had lerned art, but al his fantasye

Was turned for to lerne astrologye,

And coude a certeyn of conclusiouns

To demen by interrogaciouns,

If that men axed him in certein houres,

Whan that men sholde have droghte or elles shoures,

Or if men axed him what sholde bifalle

Of every thing, I may nat rekene hem alle. (Chaucer 1977: 92) 
(Some time ago there was a rich old codger Who lived in Oxford and who took a lodger. The fellow was a carpenter by trade, His lodger a poor student who had made Some studies in the arts, but all his fancy Turned to astrology and geomancy, And he could deal with certain propositions And make a forecast under some conditions About the likelihood of drought or showers For those who asked at favorable hours, Or put a question how their luck would fall In this or that, I can't describe them all.) (Chaucer 1977: 105)

El tono exaltado de la épica contrasta con el desenfadado de la comedia; los méritos de Teseo, con las artes deshonestas de Nicholas. Pero esta inversión de valores no sólo se debe a las diferencias entre los géneros literarios. En un sentido más profundo, tiene que ver con la capacidad carnavalesca de la fabliau para poner al mundo de cabeza.

Las teorías de Bakhtin sobre lo carnavalesco, especialmente en su estudio sobre la obra de Rabelais, sostienen que "the men of the Middle Ages participated in two lives: the official and the carnival life. Two aspects of the world, the serious and the laughing aspect, coexisted in their conciousness" (Ellis 1996: 43). También nos explica Bakhtin que las imágenes y actividades carnavalescas a menudo adoptaban la forma de parodias de las enseñanzas de lo sagrado y serio o eran una inversión grotesca de lo mismo. Ésta es la lógica rectora en el cuento del molinero. En un primer nivel, hay una atrevida parodia de la historia sagrada en la figura de John como el nuevo Noé, y de Alison y Nicholas como el resto del pueblo elegido. En un segundo nivel, nos encontramos con una inversión grotesca de los valores del mundo de la caballería y la literatura que los recrea. Ya mencionamos el contraste entre, por ejemplo, los dos personajes femeninos, que se logra con una detallada asociación de los mismos con elementos de mundos opuestos: mientras Emelye aparece en un jardín, símbolo de la naturaleza domesticada, y recoge flores blancas que representan su inocencia, es decir, es una figura alienada de lo natural por códigos culturales; Alison es descrita con analogías de lo animal, convirtiéndose en símbolo de lo instintivo, lo natural o el poder de lo terreno que, como en todo carnaval, reta al orden establecido. Cito sólo una parte de la descripción del personaje:

Fair was this yonge wyf, and ther-with-al As any wesele hir body gent and smal. 
[...] She was ful more blissful on to see

Than is the newe pere-ionette tree. (Chaucer 1977: 93)

(She was a fair young wife, her body as slender

As any weasel's, and as soft and tender;

[...] And a more truly blissful sight to see

She was than blossom on a cherry-tree.) (Chaucer 1977: 106)

El poder de los contrastes no se agota en la representación de los binomios cultura/naturaleza o amor sagrado/amor profano. El crítico Steve Ellis comenta que uno de los motivos favoritos de las fabliaux, la historia del viejo esposo engañado por la mujer joven, es un "despojamiento o destronamiento simbólico de un viejo orden por uno nuevo, particularmente en un sentido estacional" (Ellis 1996: 45. La traducción es mía) Los cuentos de Canterbury inician con un famoso himno a la primavera, como la estación en la que se renueva la vida, una celebración del fin del estatismo del invierno frente a la movilidad de la nueva estación que permite, por ejemplo, realizar un peregrinaje. En el cuento del caballero, Palamon y Arcite observan a Emily por primera vez en el mes de mayo, y vuelven a encontrarse, años después, en las afueras de la ciudad, en el mes de mayo. En la historia del mercader, perteneciente a otra sección de Los cuentos de Canterbury, nos encontramos con otra fabliau en la que el nombre del esposo engañado es Enero y el de la joven esposa es Mayo. También en el cuento del molinero, según este sistema carnavalesco de imágenes, John representa al viejo año siendo sustituido por la fuerza renovadora de la naturaleza, por la llegada de la nueva estación, encarnada en los ímpetus sexuales de Alison. Esto explica la crueldad del final de la historia. Tras una serie de peripecias, el carpintero despierta creyendo que el diluvio ha llegado y corta las cuerdas que sostienen su barril, sólo para caer sobre el tálamo en el que retozaban Alison y Nicholas. Ante el alboroto generalizado, los vecinos del pueblo despiertan y se acercan para investigar qué sucede. Se encuentran con un viejo confundido que tiene un brazo roto y dice que el segundo diluvio ha llegado y que él es el nuevo Noé. Esto provoca la burla de los testigos y libra a los amantes transgresores de cualquier acusación. La aparente injusticia del final es una representación del triunfo, como en todo carnaval, de lo temporal frente a lo eterno, de lo mundano frente a lo espiritual, y de un orden nuevo sobre un orden antiguo. Al menos por un tiempo, la fabliau y su tono socarrón han triunfado sobre el romance y su preocupación por lo trascendente. Esta inversión de las referencias también podría estar simbolizada, en otro episodio de la historia, en el beso que Absolon deposita en 
las posaderas de Alison, creyendo que se trata de su mejilla, es decir, el abajo es el arriba y viceversa.

Podríamos concluir la comparación diciendo que los dos primeros cuentos de esta obra, el del caballero y el del molinero, establecen una lógica de los contrarios que prevalecerá a lo largo de The Canterbury Tales, pero esto sería falso. Entre los dos extremos representados en estos primeros cuentos quedan encerrados un sinnúmero de posibilidades y juegos combinatorios que Chaucer explotará en textos tan complejos como el prólogo y el cuento de la comadre de Bath o la mencionada fabliau del mercader. Los dos relatos iniciales son una puerta de entrada que anuncia que todo lo establecido puede ser desconstruido y que la interpretación es, en sí misma, un tema central de la obra.

Una muestra de dichas variantes podría estar constituida por las otras dos historias que completan la primera sección. Los cuentos del administrador y del cocinero, aunque pertenecen también al género de las fabliaux, están caracterizados por una visión mucho más brutal de la sexualidad humana y el tono dominante es, por ejemplo, en el caso del relato del administrador, el de una venganza amarga, en lugar de una celebración de la vida.

De esta manera, es muy difícil precisar la posición del autor frente a los hechos narrados. Se nos enfrenta a situaciones tan diversas y se defienden o condenan visiones del mundo tan distintas y a veces contradictorias que, todo esto, unido a la multiplicación de filtros narrativos que implica la presencia de personajes inmersos en historias contadas por otros personajes que son parte de un peregrinaje narrado por un tal Chaucer que "no sabe de retórica" y que es una voz que no tiene nada que ver con un tal Geoffrey que murió en 1400 , todo esto nos deja tan confundidos como a John, el carpintero, frente a la erudición e imaginación prolífica de este maestro medieval de la poesía en lengua inglesa.

El último cuento de esta compilatio es un sermón sobre los siete pecados capitales, que mueve al arrepentimiento al grupo de peregrinos y los prepara para la llegada al santuario. El propio narrador, invadido por el ánimo de contrición, cierra la obra con unas retractaciones en las que pide perdón por todo aquello pecaminoso que haya incluido en su colección, lo cual constituye una convención de las obras medievales a la que haré honor avisando que aquí termina mi texto y que sus defectos son sólo atribuibles a la autora y jamás al genio que nos regaló un libro como The Canterbury Tales. Amén. 
$34 \square$ LO SOLEMNE Y LO FESTIVO

Bibliografía

Chaucer, Geoffrey. 1924. The Complete Works of Geoffrey Chaucer. The Canterbury Tales: Text. Londres: Oxford University Press. 1977. The Canterbury Tales. Londres: Penguin.

Coote, Stephen. 1988. English Literature of the Middle Ages. Londres: Penguin.

Ellis, Steve. 1996. Geoffrey Chaucer. E1 Reino Unido: Northcote House. 